\title{
FREEDOM OF THE JUDICIAL DISCRETION IN THE INTERPRETATION OF EVALUATIVE CATEGORIES
}

\author{
Marina S. Merezhkina \\ Volgograd State University, Volgograd, Russian Federation \\ Tatiana L. Tsytsylina \\ Volzhsky Institute of Economics, Pedagogy and Law, Volzhsky, Russian Federation \\ Stanislav V. Shiro \\ Volgograd State Social Pedagogical University, Volgograd, Russian Federation
}

\begin{abstract}
Introduction: evaluative categories in the Russian civil law are quite widespread. These categories include reasonableness in determining the amount of losses, a significant drawback, good faith of the acquirer, a reasonable period of time, and others. There are different approaches to the definition of the institute of evaluative categories. To date, no single approach to the concept of "evaluative category" has been developed. Evaluative concepts are fuzzy, inaccurate and abstract. In this regard, the main purpose of this study is to determine the mechanism of application of the analogy of the law for the purpose of official interpretation and explanation of evaluative concepts. It is necessary to simplify the task of distinguishing between statements of fact and evaluative judgments. Methods: the study used both the general scientific methods (the dialectical method of cognition, analysis, synthesis, formal logical method, etc.) and the specific scientific methods (formal legal, analytical, etc.). Results: the paper assesses the implementation of approaches to the interpretation of evaluative categories in cases with the use of judicial discretion. The main groups of evaluative categories are identified. Conclusions: as a result of the study, the need to create additional mechanisms for the use of evaluative categories in the adjudication of civil disputes is identified. It is advisable to fix the limits of qualitative and quantitative characteristics of evaluative categories.
\end{abstract}

Key words: civil process, evaluative category, judicial discretion, reasonableness, judicial practice.

Citation. Merezhkina M.S., Tsytsylina T.L., Shiro S.V. Freedom of the Judicial Discretion in the Interpretation of Evaluative Categories. Legal Concept, 2019, vol. 18, no. 2, pp. 79-83. (in Russian). DOI: https://doi.org/10.15688/

\section{СВОБОДА СУДЕБНОГО УСМОТРЕНИЯ ПРИ ТОЛКОВАНИИ ОЦЕНОЧНЫХ КАТЕГОРИЙ}

\author{
Марина Сергеевна Мережкина \\ Волгоградский государственный университет, г. Волгоград, Российская Федерация \\ Татьяна Леонидовна Цыцылина \\ Волжский институт экономики, педагогики и права, г. Волжский, Российская Федерация
}

\section{Станислав Викторович Широ}

Волгоградский государственный социально-педагогический университет, г. Волгоград, Российская Федерация 
Введение: оценочные категории широко распространены в российском гражданском праве. К ним, в частности, относятся разумность при определении размера убытков, существенный недостаток, добросовестность приобретателя, разумный срок и другие. Существуют различные подходы к определению института оценочных категорий, однако до настоящего времени не выработана единая точка зрения относительно понятия «оценочная категория». Оценочные понятия являются нечеткими, неточными и абстрактными. В связи с этим, основной целью настоящего исследования является определение механизма применения аналогии закона с целью официального толкования и разъяснения оценочных понятий. Необходимо упростить задачу разграничения утверждений о фактах и оценочных суждений. Методы: в ходе исследования были применены как общенаучные (диалектический метод познания, анализ, синтез, формально-логический метод и др.), так и частно-научные методы (формально-юридический, аналитический и др.). Результаты: дана оценка реализации подходов к толкованию оценочных категорий при рассмотрении дел с использованием судебного усмотрения. Выделены основные группы оценочных категорий. Выводы: проведенное исследование позволило выявить необходимость создания дополнительных механизмов для применения оценочных категорий при рассмотрении гражданско-правовых споров. Целесообразно закрепить пределы качественных и количественных характеристик оценочных категорий.

Ключевые слова: гражданский процесс, оценочные категории, судебное усмотрение, разумность, судебная практика.

Цитирование. Мережкина М. С., Цыцылина Т. Л., Широ С. В. Свобода судебного усмотрения при толковании оценочных категорий // Legal Concept = Правовая парадигма. -2019 . - Т. 18, № 2. - C. 79-83. DOI: https://doi.org/10.15688/lc.jvolsu.2019.2.12

\section{Введение}

Оценочные категории в праве - это осознанная, проверенная годами необходимость, без которой справедливое и учитывающее конкретные условия дела судебное решение, на наш взгляд, невозможно. При разрешении однотипных дел не должны использоваться взаимоисключающие подходы и кардинально противоположные суждения с применением оценочных категорий, так как последние позволяют избежать механического применения норм к разным жизненным ситуациям, однако не должны способствовать неправомерным действиям при судопроизводстве.

Поэтому в разъяснениях высшей судебной инстанции говорится о «необходимости разграничивать имеющие место утверждения о фактах, соответствие действительности которых можно проверить, и оценочные суждения, мнения, убеждения, которые не могут быть проверены на предмет их соответствия действительности, так как являются выражением субъективного мнения» [4, с. 23].

\section{Понятие «судебное усмотрение» в правоохранительной деятельности}

Концепция оценки является одним из средств, с помощью которых законодатель предусматривает подсознательный характер регулирования. Она существует для выполнения различных функций. Субъекты наделены возможностью самостоятельно регулировать свое поведение, но в то же время концепция оценки позволяет установить рамки индивидуального регулирования - правовые рамки, в которых юридические лица могут по своему усмотрению определять содержание своих прав и обязанностей, условия их создания и т. д.

К отдельной группе оценочных понятий относится «судебное усмотрение», сущность которого раскрывается в научных исследованиях. А. Т. Боннер определяет его как «деятельность суда по отысканию наиболее оптимального решения в общих рамках закона, которая обусловлена поставленными перед судом задачами, соответствует интересам государства и общества и основана на познании объективной действительности» [1, с. 46].

Можно считать, что судебное усмотрение - это особый вид правоохранительной деятельности, регулируемый нормами, суть которого - дать суду необходимые полномочия для решения спорного вопроса на началах добросовестности, справедливости и основ морали. Понятия оценки - это абстрактные понятия, отражающие эмпирические свойства явлений путем определения типов их прав, имеющих относительно конкретное содержание и определяющихся исследователем на основании усмотрения. 
Разнообразие процессуальных и материальных отношений позволяет определить оценочные категории, которые четко обозначены, например, в Гражданско-процессуальном кодексе Российской Федерации (далее ГПК РФ) (необходимые доказательства, уважительность пропуска процессуального срока и др.).

ГПК РФ допускает восстановление пропущенных процессуальных сроков судом по уважительным причинам в порядке исключительности, при доказанности обоснованности причин пропуска сроков, препятствовавших объективно совершению процессуальных действий, таких как подача жалобы и т. п. (ст. 112, ч. 2 ст. 376 , ч. 2 ст. 391.2 и ч. 2 ст. 391.11 ГПК РФ). Оценочные категории могут также содержаться в актах высших судебных органов России.

\section{Разумность как оценочное понятие}

В качестве иллюстрации рассмотрим оценочное понятие «разумность», которое часто и, на наш взгляд, успешно использует судебная практика при рассмотрении гражданскоправовых споров, например, при определении размера убытков. В соответствии с п. 5 ст. 393 Гражданского кодекса Российской Федерации (далее - ГК РФ) допускается установление размера подлежащих возмещению убытков с разумной степенью достоверности. Таким образом, в ГК РФ закреплен принцип разумной достоверности установления размера убытков. Введение указанного оценочного понятия в ГК РФ стало позитивным явлением, упростившим положение потерпевшего.

Пункт 5 ст. 393 ГК РФ начал действовать в указанной редакции с 01.06.2015, следовательно, на сегодняшний день можно анализировать практику применения этой нормы.

В настоящее время позиция законодателя по применению нормы о разумной достоверности убытков подтверждена Верховным судом РФ. В Постановлении Пленума Верховного Суда РФ от 24.03.2016 № 7 «О применении судами некоторых положений ГК РФ об ответственности за нарушение обязательств» Верховный суд РФ отметил, что согласно п. 5 ст. 393 ГК РФ суд может отклонить требование кредитора о возмещении убытков за нарушения условий исполнения обязательства только в том случае, если размер ущерба не может быть определен с достаточной уверенностью. При указанном отклонении суд определяет сумму убытков, подлежащих возмещению, учитывая конкретные обстоятельства дела, основывая свое решение на принципах справедливости и соразмерности ответственности за совершенное нарушение.

\section{Судебная практика применения категории «разумность»}

Анализ судебной практики применения категории «разумность» при разрешении гражданско-правовых споров демонстрирует активную и разнообразную позицию суда.

Согласно правовой позиции Конституционного Суда РФ, изложенной в постановлении от 13.12.2016 № 28-П [3, с. 36], возможно снижение судом размера компенсации ниже низшего предела, установленного ст. 1301, 1311 и 1515 ГК РФ, если суд предусматривает определенные условия. Такое сокращение возможно только по требованию ответчика, если: убытки рассчитаны с достаточной достоверностью и превышение доказано ответчиком; правонарушение совершалось виновным лицом в первый раз; использование объектов интеллектуальной собственности при отсутствии прав на них не являлось неотъемлемой частью деяния ответчика и не являлось грубым (например, если продавец не знал о фальсификации продаваемой продукции).

В качестве примера активного использования оценочной категории «разумность» при вынесении решения приведем следующее гражданское дело. Определением Арбитражного суда Ханты-Мансийского автономного округа - Югры от 16.05.2018 по делу № А75$13690 / 2016$ было отказано в удовлетворении заявления ООО «Автотриада» о включении 200030000 руб. в реестр требований кредиторов должника в рамках дела о несостоятельности (банкротстве) ООО Транспортная компания «Призвание». Не согласившись с судебным актом, ООО «Автотриада» обратилось в суд апелляционной инстанции. Постановлением Восьмого арбитражного апелляционного суда от 04.10.2018 в удовлетворении апелляционной жалобы было отказано. Суд сослал- 
ся на то, что «разумные экономические мотивы выдачи должником векселя на сумму 200000000 руб. ООО “Автотриада" не могут быть признаны установленными в условиях отсутствия доказательств экономического представления заявителем в пользу должника... Кроме того, заявителем не раскрыты разумные причины непредъявления требований к должнику на протяжении длительного времени... Соответствующее поведение не может быть признано разумно ожидаемым от участника гражданско-правовых отношений, целью которого является получение прибыли, что следует из организационно-правовой формы заявителя. Совокупность изложенного свидетельствует об отсутствии разумного обоснования выдачи ООО ТК “Призвание” заявителю вышеуказанного векселя и совершении указанной сделки между аффилированными лицами». «Поэтому само по себе наличие судебного приказа означает лишь то, что требование заявителя о выдаче судебного приказа должником не оспорено, то есть признано. Такое признание имеет правовые последствия только для заявителя и должника и ни для кого больше. Такое признание, кроме прочего, не предрешает безусловную достоверность хозяйственной операции, лежащей в основании выдачи векселя, которая в настоящем деле не раскрыта» [2].

Приведенный судебный акт демонстрирует активную, уверенную позицию суда в обосновании своего решения оценочными понятиями.

\section{Выводы}

Проведенный анализ показал, что важно различать утверждения о фактах и оценочные суждения. В действующем законодательстве отсутствуют понятия указанных категорий, не раскрыто их содержание. В связи с этим, законодателю при включении в нормативные акты норм, содержащих оценочную категорию, в обязательном порядке следует в общих чертах ее конкретизировать, либо рекомендовать Верховному Суду РФ сформулировать соответствующие разъяснения. Необ- ходимо определение механизма применения аналогии закона с целью официального толкования и разъяснения оценочных понятий. Необходимо упростить задачу разграничения утверждений о фактах и оценочных суждений.

\section{СПИСОК ЛИТЕРАТУРЫ}

1. Боннер, А. Т. Советский закон и судебное усмотрение / А. Т. Боннер // Советское государство и право. - 1979. - № 6. - С. 46-52.

2. Постановление Восьмого арбитражного апелляционного суда от 04.10.2018 по делу № А7513690/2016. - Электрон. текстовые дан. - Режим доступа: http://8aas.arbitr.ru.

3. Постановление Конституционного Суда РФ от 13.12.2016 № 28-П «По делу о проверке конституционности подпункта 1 статьи 1301, подпункта 1 статьи 1311 и подпункта 1 пункта 4 статьи 1515 Гражданского кодекса Российской Федерации в связи с запросами Арбитражного суда Алтайского края» // Вестник Конституционного Суда РФ. 2017. - № 2 .

4. Постановление Пленума Верховного суда РФ № 3 от 24.02.2005 «О судебной практике по делам о защите чести и достоинства граждан, а также деловой репутации граждан и юридических лиц // Бюллетень Верховного суда РФ. - 2005. - № 4.

\section{REFERENCES}

1. Bonner A.T. Soviet Law and Judicial Discretion. Soviet State and Law, 1979, no. 6, pp. 46-52. (in Russian).

2. Decision of the Eighth Arbitration Court of Appeal of 4 October 2018 in Case no. A75-13690/ 2016. URL: http://8aas.arbitr.ru. (in Russian).

3. The Decision of the Constitutional Court of the Russian Federation from 28.13.12.2016 N-P “On Business about Check of Constitutionality of Paragraph 1 of Article 1301, Sub-paragraph 1 of article 1311 and subparagraph 1 of paragraph 4 of article 1515 of the Civil code of the Russian Federation in connection with inquiries Arbitration court of the Altai region". Bulletin of the Constitutional Court of the Russian Federation, 2017, no. 2. (in Russian).

4. Resolution of the Plenum of the Supreme Court no. 3 of February 24, 2005 “On Judicial Practice in Cases of Protection of Honor and Dignity of Citizens, as Well as Business Reputation of Citizens and Legal Entities. Bulletin of the Supreme Court, 2005, no. 4. (in Russian). 


\section{Information about the Authors}

Marina S. Merezhkina, Candidate of Sciences (Jurisprudence), Associate Professor, Department of Business Law, Arbitration and Civil Procedure, Volgograd State University, Prosp. Universitetsky, 100, 400062 Volgograd, Russian Federation, meregkina@mail.ru, https://orcid.org/0000-0001-7158-5024

Tatiana L. Tsytsylina, Candidate of Sciences (Jurisprudence), Associate Professor, Department of Civil Law Disciplines, Volzhsky Institute of Economics, Pedagogy and Law, Sovetskaya St., 6, 404111 Volzhsky, Russian Federation, meteorain@yandex.ru, https://orcid.org/0000-0003-1729-4220

Stanislav V. Shiro, Candidate of Sciences (Pedagogy), Associate Professor, Head of the Department of Law and Methods of Teaching Law, Volgograd State Social Pedagogical University, Prosp. im. V.I. Lenina, 27, 400066 Volgograd, Russian Federation, stanislav_shiro@mail.ru, https://orcid.org/0000-0002-9725-698X

\section{Информация об авторах}

Марина Сергеевна Мережкина, кандидат юридических наук, доцент кафедры предпринимательского права, арбитражного и гражданского процесса, Волгоградский государственный университет, просп. Университетский, 100, 400062 г. Волгоград, Российская Федерация, meregkina@mail.ru, https://orcid.org/0000-0001-7158-5024

Татьяна Леонидовна Цыщылина, кандидат юридических наук, доцент кафедры гражданскоправовых дисциплин, Волжский институт экономики, педагогики и права, ул. Советская, 6, 404111 г. Волжский, Российская Федерация, meteorain@yandex.ru, https:/orcid.org/0000-0003-1729-4220

Станислав Викторович Широ, кандидат педагогических наук, доцент, заведующий кафедрой права и методики преподавания права, Волгоградский государственный социально-педагогический университет, просп. им. В.И. Ленина, 27, 400066 г. Волгоград, stanislav_shiro@mail.ru, https://orcid.org/0000-0002-9725-698X 